\title{
Trayectorias migratorias y consumo de televisión local del país de origen en el marco de la construcción de una comunidad transnacional Hugo García Álvarez*
}

\section{Resumen}

Este documento analiza el papel que desempeña una televisora local mexicana entre la comunidad migrante originaria de Monterrey, México, en Houston, Texas. Mediante entrevistas focalizadas fue posible identificar algunas estrategias usadas por los televidentes para vincularse con la región a través de la televisión, lo cual puso de manifiesto que la señal de Multimedios tiene un papel similar de arraigo y tradición al que desempeñan otros consumos culturales. Como ejemplo de esto se pueden citar los casos de los dos informantes de segunda generación que activamente buscan su propia identidad como mexico-americanos y el importante papel que la televisión y la frontera tienen en esta búsqueda de lo mexicano-norteño. Este trabajo concluye que además de las redes sociales que posibilitan, alientan y mantienen la llegada de nuevos migrantes mexicanos a Texas, el papel que juega la presencia del "Canal 12" en esta situación transnacional como ancla de la identidad regional es de hecho resultado de las dinámicas fronterizas construidas sobre la base de una continuidad geográfica.

Palabras clave: migración, consumo cultural, televisión, identidad regional, comunidad transnacional

\begin{abstract}
The paper explores the role a regional Mexican television channel has in the maintenance of cultural identity and cultural links with their home city of former Monterrey, Mexico, between inhabitants who migrated to Houston, Texas. Through interviews it was possible to identify some strategies for TV viewers to reinforce their sense of belonging to their former local community and avoid their emotional distancing from it and deal with the border. The cases described here show how some people search their identity as Mexican-Americans and the role this TV signal can play, along with the dynamics the border impose on them. The study concludes that in addition to the initial social and familiar networks that facilitated the arrival of newcomers, the availability of "Canal 12" helps to understand a community in a transnational setting as a manifestation of the conditions of border relations and the continuity that this bi-national space provide to maintain strong cultural and symbolic ties with their home region in Northeast Mexico.
\end{abstract}

Keywords: migration, cultural consumption, television, regional identity, transnational community.

* Doctorado en el programa de Estudios Humanísticos del ITESM, fue investigador asistente en el Centro de Investigaciones en Comunicación del Tecnológico de Monterrey donde colaboró en el proyecto Consumo de Medios Audiovisuales en el Noreste de México. Actualmente es profesor-investigador adscrito al Centro de Investigaciones Sociales y Territoriales de la Universidad Autónoma del Carmen. Correo electronico: hgarcia@pampano.unacar.mx y hugogarciaa@gmail.com 


\section{Introducción}

En este estudio se pretende identificar aquellas prácticas culturales relacionadas con el consumo de medios que contribuyen a perfilar una región sociocultural en función de las manifestaciones culturales y de sus consumos mediáticos, su recepción y apropiación. Ya que como identifica Pedroza (2004:149) "el consumo sería un espacio de negociación de sentido donde se estarían demarcando rasgos de pertenencia identitaria".

Para lograr lo anterior se plantea describir y relacionar las particularidades del proceso migratorio de televidentes de la programación de Multimedios en Houston, Texas, con su consumo de la señal televisiva.

El proceso histórico de conformación de las relaciones bilaterales entre Nuevo León y Texas se remonta a la definición del Río Bravo como frontera entre los dos países. Desde ese momento, una gran cantidad de flujos comerciales y mercantiles empezó a tener lugar. Historiadores como Mario Cerutti (2000:27) se han encargado de reconstruir este proceso de conformación de la "región binacional" que continúa hasta nuestros días.

Durante el Programa Bracero, entre 1942 y 1964, Monterrey fue punto de partida para el envío de mano de obra mexicana hacia Texas (Hernández, 2002). Muchos regiomontanos y nuevoleoneses participaron de esas migraciones laborales e igual que los braceros de otras regiones algunos se quedaron a vivir en Estados Unidos, incrementando así los vínculos culturales de esta ciudad del noreste de México con distintas poblaciones del vecino país.

La intensificación de los flujos migratorios internacionales urbanos que tienen como punto de partida el área metropolitana de Monterrey, así como la creación de la infraestructura social que permite hablar de una conexión entre Monterrey y ciudades como Houston u otras ciudades más alejadas de la frontera con México pueden ser considerados un fenómeno relativamente reciente. Tal vez ésta sea la razón por la que existen escasos estudios al respecto, y en general sobre migración y transnacionalismo en el noreste del país.

Zúñiga (1998) apunta además que detrás de estas dicotomías fronterizas está también una relación de lo propio y lo ajeno institucional construido desde las estructuras de poder. Es decir, que en la situación particular de la frontera México-Estados Unidos también debe destacarse esta di- 
mensión de reproducción de "valores" nacionales frente a los extranjeros promovidos por las instituciones oficiales.

Hernández-León (2008) prefiere hablar de un "circuito migratorio", ya que este concepto también contempla el aspecto sociopolítico del fenómeno, que al menos en el caso que él estudia supone más que una desaparición de fronteras, una ampliación de la misma regulada hasta cierto punto por las políticas a propósito implementadas por cada uno de los países.

En estas circunstancias los migrantes tienen que recurrir a aquellos elementos que regulan y simplifican el proceso migratorio apoyándose tanto en redes sociales como en las industrias migratorias, entendidas éstas como una matriz de servicios y actividades organizadas alrededor del movimiento internacional de personas (Hernández-León, 2008:24-25). En un sentido similar, Sandoval (2008) describe lo que él identifica como infraestructuras que sustentan y al mismo tiempo proveen de medios para el movimiento de las personas y facilitan la repetición del desplazamiento y en algún sentido acompañan al migrante mientras se encuentra fuera de su lugar de origen.

Avtar Brah (1996) ha propuesto el concepto de diáspora ampliando la noción convencional de dispersión de una población nacional (reconociendo el origen del término como asociado a la dispersión judía después del exilio en Babilonia) a un espacio diferente, relacionándolo con las modernas migraciones de poblaciones de países en desarrollo a países industrializados en el marco del capitalismo mundial:

Las diásporas son lugares para la formación de comunidades a largo plazo, si no es que permanentes, incluso en el caso de que algunos miembros de la comunidad se muevan de ahí. La palabra diáspora a veces evoca imágenes de traumas, separación y dislocación, importantes aspectos propios de la experiencia migratoria. [Las diásporas] enfrentan ámbitos culturales y políticos donde las memorias individual y colectiva chocan, se reensamblan y se reconfiguran (Brah, 1996:193).

Este autor concentra su análisis en las relaciones entre países colonizados y los colonizadores e introduce el concepto de espacio de la diáspora (space diaspora) (Brah, 1996:181) para referirse a la relación transgenera- 
cional entre aquellos que emigraron, y las relaciones que se establecen con aquellos que se quedaron. Así, dadas las condiciones de "dispersión forzada y renuente" (Barker, 2003:123), la comunidad diaspórica se relaciona con la comunidad de origen en la dinámica social del recuerdo y la conmemoración más que en una unidad igualitaria.

Para clarificar estos fenómenos dentro de su propio corpus, los trabajos sobre audiencias de origen hispanoamericano en Estados Unidos han desarrollado una línea de estudios que centrada en los medios mismos habla de medios étnicos (ethnic media) (Kanellos y Martell, 2000; Mayer, 2001; Subervi-Velez, 1986) y apunta a la existencia de aquellos que satisfacen las necesidades de grupos específicos en momentos singulares de su migración y cómo las condiciones particulares de la migración mexicana -caso de estudio de este trabajo- se ha dado por oleadas rastreables desde el siglo pasado (De León, 2001).

Los trabajos de Rubén Hernández-León (1997, 1999, 2002 y 2004) sobre la conexión Monterrey-Houston son tomados aquí como la base para el análisis de este fenómeno. Sus investigaciones destacan, principalmente, la importancia económica de la organización social transnacional que sostiene esta conexión y las redes sociales que conforman estos vínculos transnacionales.

\section{Nuevoleoneses en Houston}

De acuerdo con el censo de población de Estados Unidos 30\% de los habitantes de la ciudad de Houston, Texas, es de origen mexicano. De los dos millones de habitantes, 640 mil son mexicanos. El siguiente grupo nacional hispanoamericano de acuerdo con su peso poblacional en Houston son los puertorriqueños con siete mil habitantes (US Census Bureau, 2007).

Resulta imposible establecer qué proporción de esos habitantes es originaria de Nuevo León, pero de acuerdo con José Borjón, cónsul mexicano para asuntos comunitarios,

[...] Nuevo León es el cuarto estado más representado, aquí en Houston [se refiere a la jurisdicción del Consulado, que contempla 37 condados del este de Texas y el estado de Louisiana], primero San Luis, luego Guanajuato, luego Tamaulipas y luego Nuevo León (José Borjón, 20 de junio de 2007). 


\section{Cuadro 1}

Distribución de la población de Houston, Texas, de acuerdo con la raza

\begin{tabular}{|l|r|c|c|c|}
\hline & Estimado & Margen de error & Porcentaje & Margen de error \\
\hline Población total & $2,034,749$ & $+/-10,527$ & $100 \%$ & $(\mathrm{X})$ \\
\hline $\begin{array}{l}\text { Hispano o latino de } \\
\text { cualquier raza }\end{array}$ & 848,113 & $+/-8,146$ & $41.7 \%$ & $+/-0.3$ \\
\hline Mexicano & 642,844 & $+/-9,967$ & $31.6 \%$ & $+/-0.5$ \\
\hline Puertorriqueño & 7,319 & $+/-1,147$ & $0.4 \%$ & $+/-0.1$ \\
\hline Cubano & 5,68 & $+/-1,161$ & $0.3 \%$ & $+/-0.1$ \\
\hline Blanco & $1,118,200$ & $+/-10,319$ & $55.0 \%$ & $+/-0.5$ \\
\hline Negro o afroamericano & 502,563 & $+/-5,975$ & $24.7 \%$ & $+/-0.3$ \\
\hline
\end{tabular}

Fuente: U.S. Census Bureau, Encuesta a comunidad americana 2005-2007.

De acuerdo con los trabajos de Hernández, entre el área metropolitana de Monterrey y Houston circulan muchos bienes y personas. Sobre todo, el autor destaca la importancia de las remesas y las redes en los ámbitos familiar y vecinal. En sus textos se habla de un "aquí" y un "allá". El "allá" (Houston, Texas, o "el gabacho") representa aquello que permanece distante y cuyo conocimiento en ocasiones es una "aventura" (HernándezLeón, 1999).

En abril de 2005 entró en servicio la señal de Multimedios Televisión, el canal local de mayor rating y de mayor arraigo en Monterrey, Nuevo León, en el área metropolitana de Houston a través de un convenio con la televisora Lotus TV que transmite en el canal кHLm-43, clasificado como de baja potencia, propiedad de Jim Kalmenson. Según reportes de prensa ellos compran la señal de Multimedios justo para el público de origen regiomontano. En una entrevista concedida al periódico Rumbo, reconocen que el programa con más éxito es "Futbol al Día". Al inicio del convenio la televisora producía un noticiero local que se canceló y a partir de 2007 sólo programa los noticieros producidos en Monterrey por Multimedios (García-Palafox y Rangel, 2006).

A partir de agosto de 2007, Multimedios Televisión inició la transmisión de algunos programas de su barra nocturna ("Night Show" con Víctor Luján; "Pura Energía”, con Jesús Soltero) a través del canal KAZH-TV 57 
Tu Visión Houston, que sí tiene transmisión por los sistemas de cable de la ciudad.

El mercado televisivo de Houston, ciudad en la que 24\% de los hogares habla español, ya estaba ocupado por otras cinco estaciones de televisión que transmitían en este idioma. Houston es el cuarto mercado de habla hispana en Estados Unidos, detrás de Los Ángeles, Nueva York y Miami (Davis, 2005).

Como ya se comentó antes, resulta complicado establecer números definitivos cuando se habla de la población de origen mexicano en Houston, sin embargo, César Rincón, gerente de TV Informa (кHLm 43 Houston), el canal que transmite la señal de Multimedios, dice:

La razón por la que escogimos hacer el proyecto en conjunto con la programación de Multimedios es precisamente por eso [la gran cantidad de personas de origen regiomontano], se estima que el 60 o $70 \%$ de los mexicanos que viven en el área de Houston son de Monterrey o de las áreas vecinas, de Nuevo León o de los estados fronterizos, del corredor de la frontera... y es la misma área donde multimedios tiene cobertura (César Rincón, 19 de junio de 2007).

Aunque no ofreció fuentes para sus datos, esta proporción es la que usaba en su documentación para clientes potenciales en la venta de publicidad para el canal. De acuerdo con las previsiones de Rincón, alrededor de $60 \%$ de los hispanos en Houston no está suscrito a ningún sistema de televisión de paga, por lo que ése era su público objetivo.

Con más de 30 años como señal de televisión, Multimedios es un sistema de televisoras con presencia regional en las principales ciudades del noreste de México, especialmente en las capitales de los estados de esta zona del país (Carmona, 2007). Con sede en Monterrey, Nuevo León, y a través de sus programas y personalidades, multimedios ha alcanzado un amplio reconocimiento entre la población de su ciudad sede y de la región.

Actualmente la señal de esta televisora también está disponible fuera del noreste de México en el norte de Veracruz y en Ciudad Juárez, y en el Bajío con señales en León e Irapuato, Guanajuato. 


\section{Medios y migración mexicana}

La televisión se ha integrado a nuestras vidas de muy distintas maneras. Hay hogares en los que la televisión casi cumple una jornada de ocho horas y acompaña hasta cierto grado cada una de nuestras actividades exponiéndonos a ese sistema de mensajes que parece tener un papel significativo en nuestra aculturación y socialización, estableciendo lecciones acerca de qué existe, qué es importante y qué es correcto, a través de la repetición y el consumo ritual (Morgan y Shanahan, 1997).

La extensión de la comunidad expuesta a los mismos mensajes se amplía con las señales satelitales. La televisión trasciende barreras geográficas y culturales y se ha convertido en fuente de información y socialización común para poblaciones heterogéneas (Gerbner, Morgan y Signorielli, 1996).

Esta misma ubicuidad de los mensajes televisivos ha hecho posible, en un contexto migratorio, que comunidades separadas tengan acceso a transmisiones televisivas producidas en sus países de origen. Entendido así, el transnacionalismo puede hacer referencia a relaciones individuales, comunitarias, o aquellas sostenidas por instituciones formales, e incluso por los estados nacionales (Portes, 2005).

Podemos suponer que tanto la televisión como los espectadores comparten significados culturales y una lengua particular con sus reglas que les permite atribuir significación a objetos y eventos (Habermas, 1993:198), compartiendo un mundo de referencias comunes a los individuos. El discurso de la televisión se articula sobre la base del discurso del televidente y al mismo tiempo lo enriquece y reconstruye, integrándose en un mundo de vida cambiante, organizado dialécticamente.

La televisión es parte de la vida y como tal dialoga con la vida diaria del individuo; un sistema de valores compartido, una idea del mundo que se entrelaza y que por tanto es necesario profundizar en los mecanismos y las reglas mediante las cuales es posible este diálogo.

En el marco de la construcción de una audiencia y una identidad mediática, Vicki Mayer (2001:293) se refiere a un hito en la construcción de la identidad migratoria para el caso de los migrantes mexicanos en San Antonio, Texas. Comenta la autora que durante los años de la Revolución mexicana el periódico La Prensa, fundado por un mexicano, tuvo éxito en- 
tre otros migrantes mexicanos de clase media exiliados en Texas durante los años de la guerra, proporcionando información sobre la Revolución y sobre el acontecer diario del país.

La autora sugiere que los medios dirigidos a personas de origen mexicano y latino en general, al menos para el caso de San Antonio, han pasado de un inicio segmentado, medios pequeños para públicos específicos, a fragmentados, medios grandes que se diversifican para llegar a grupos demográficos específicos. Esta distinción pudiera aplicar para describir esta primera etapa de la penetración del grupo Multimedios en Texas.

Otra explicación de este fenómeno pudiera encontrarse, para el caso particular de Houston, en lo que Arnoldo de León encontró en la comunidad mexicana en Houston en la década de los años treinta; según él, en ese momento existía una brecha generacional manifiesta en "las necesidades diferentes, aunque comunes, de quienes se adherían a 'lo mexicano’ y quienes accedían a 'lo americano”" (De León, 2001:70-71). Estas diferencias relacionadas con el paso del tiempo y con el asentamiento permanente de una comunidad en un lugar distinto al propio pudiera responder a lo que Anne-Marie Fortier (2002:114) comenta en cuanto a que "los inmigrantes constantemente están negociando su posición entre naciones, entre ‘de dónde son’ y 'dónde están’ y a dónde van, creando identidades en el proceso como puntos de sutura momentáneos que estabilizan el flujo”. Si consideramos que los recursos de una generación y otra son diferentes, las respuestas también serán diferentes.

Las relaciones de una comunidad de televidentes con un medio de comunicación particular pueden sufrir modificaciones con el paso del tiempo, por lo tanto añadir esta dimensión temporal pudiera ayudar a comprender mejor el papel que tiene el medio de acuerdo con el lugar de consumo como la relación personal del televidente en diferentes momentos de su vida.

En la medida en que la televisión ocupa un lugar "en los ritmos y rutinas de la vida doméstica" (Barker, 2003), el medio mismo se convierte también en un espacio que enfrenta las relaciones sociales y la vida diaria de los televidentes que conforman la región transnacional. Es frente a la televisión como se define el hogar.

Con base en la discusión teórica previa, este trabajo se propone analizar esta posible condición multilocal de la comunidad regiomontana y el 
papel que pudiera tener una señal de televisión disponible ahora en Estados Unidos. Además se planteó describir la circulación de las personas y su imaginario entre Monterrey y Estados Unidos, considerando dicotomías propias de la frontera, como lo mexicano-la tradición enfrentado a lo que viene de Estados Unidos; lo moderno; la intimidad-lo visible; los valores nacionales frente a lo ajeno, lo extranjero, y cómo se integra el canal en éstas y a la nueva situación de los migrantes en la comunidad de destino.

Este estudio pretende identificar aquellas prácticas culturales relacionadas con el consumo de medios que contribuyen para perfilar una región sociocultural en función de las manifestaciones culturales y de sus consumos mediáticos y su recepción y apropiación (Pedroza, 2004).

Para lograr lo anterior se propuso describir y relacionar las particularidades del proceso migratorio de televidentes de la programación de Multimedios en Houston, Texas, con su consumo de la señal televisiva y sus trayectorias migratorias, sus vínculos con la región y cómo estos elementos contribuyen a la construcción de una región transnacional.

\section{Procedimiento}

Debido a su carácter flexible y abierto en el que el entrevistado transmite su interpretación de la situación de estudio (Ruiz, 1999:166), la entrevista como estrategia metodológica permite integrar no sólo los diferentes momentos del consumo de la programación de Multimedios a partir de la migración, sino obtener información sobre su consumo de medios actuales y previos, así como sobre la relación de los desplazamientos de personas y circulaciones de medios y las relaciones de consumo de bienes culturales provenientes de Monterrey o de la región circundante en la conformación de una comunidad transnacional.

Para la selección de los informantes se consideró, antes que su representatividad, su competencia (Bernard, 1995:165), en tanto que miembros de la comunidad transnacional bajo estudio.

La selección de la entrevista semiestructurada en este trabajo obedeció también a que dadas las condiciones del trabajo de campo, en una ciudad y país diferentes a los del investigador es mejor este método que la entrevista libre, en la cual se supone habría más de una oportunidad de encon- 
trarse con el informante y funciona mejor en situaciones de inmersión etnográfica en la comunidad (Bernard, 1995:209).

Es necesario recalcar la situación migratoria irregular de muchos de los mexicanos y nuevoleoneses que viven en Estados Unidos, lo que los pone sobre alerta ante cualquier intento de contacto y supone dificultades especiales para el trabajo de campo, lo cual se sumó a un ambiente especial de combate a la migración ilegal en la ciudad de Houston, ya que durante una de las estancias en esta ciudad ocurrió una redada especialmente llamativa para detener a trabajadores ilegales, casi todos mexicanos, en una fábrica de donas (Pinkerton y Carroll, 2008). Esta redada fue tan publicitada que provocó que durante dos días se detuvieran los trabajos de construcción en un edificio cercano al lugar donde estaba viviendo el investigador, donde era común oír español y presumiblemente la planta laboral era en gran medida ilegal.

Para emplear el tiempo de las estancias con mayor eficiencia, se optó por una variante del procedimiento conocido como "bola de nieve" para identificar a informantes potenciales. En la mayoría de los casos hubo al menos dos comunicaciones previas a la entrevista larga con cada una de las personas que participaron.

El número de informantes que integró la muestra final fue de 18, 10 mujeres y ocho hombres, con edades entre los 16 y los 60 años; tres parejas de informantes están emparentados entre sí, dos padre e hijo y un par de hermanos. Cuatro estudiantes de preparatoria, dos jubilados, dos amas de casa, dos estudiantes de posgrado; el resto eran trabajadores asalariados.

\section{Resultados: frontera y televisión}

Son dos las razones principales por las que es importante indicar el modo general en que los informantes entraron a Estados Unidos y cómo se asentaron finalmente en Houston: la primera es porque este trabajo se inscribe en el marco de la discusión sobre relaciones y regiones transnacionales construidas históricamente que se manifiestan en la existencia de infraestructuras o industrias migratorias, por lo que es necesario relacionar los antecedentes migratorios con estos factores. Además, es necesario relacionar la trayectoria migratoria de los informantes con la disponibilidad 
relativamente reciente del canal en Houston. La señal de Multimedios se empezó a transmitir en 2005, por lo que dependiendo del momento de entrada a Estados Unidos y de sus posibilidades de viaje, los informantes tuvieron que reestablecer una relación con el canal o efectivamente tuvieron la posibilidad de "viajar", de desplazarse con ella.

Sólo se detectó un caso en que el estatus migratorio tuvo un impacto en la capacidad de desplazamiento del informante. La señora Cecilia Soto ${ }^{1}$ informó que tenía 17 años sin viajar a Monterrey, pero que en los meses siguientes a la entrevista por fin arreglaría su situación migratoria y entonces podría salir de Estados Unidos sin correr el riesgo de no poder volver.

Todos los demás viajan con regularidad variable a Monterrey y han estado ahí al menos una vez en los últimos dos años.

A pesar de las diferencias en el modo en que los entrevistados llegaron a la ciudad de Houston, casi todos lo hicieron en compañía de algún familiar, en su mayoría familiares consanguíneos, padres, y algunos con su cónyuge.

Hubo un caso único, que sólo vamos a usar de referencia, de migración sin apoyo de redes familiares de ningún tipo. Fernando Méndez nació en California mientras su padre cursaba estudios de posgrado, al terminar sus estudios, la familia volvió a Monterrey donde Fernando hizo sus estudios universitarios. El hecho de haber nacido en Estados Unidos le ayudó para poder aplicar para un trabajo en Dallas como diseñador industrial, ya que ser ciudadano estadounidense por nacimiento le daba ventajas ante sus empleadores. Después de un tiempo se mudó a Houston a un nuevo trabajo. Su experiencia migratoria se ajusta a una modalidad reciente en la que empresas estadounidenses reclutan trabajadores mexicanos con formación profesional.

La modalidad migratoria más frecuente entre los informantes es el desplazamiento de toda la familia nuclear, iniciada con alguno de los miembros, especialmente el esposo o el padre. Los miembros de la familia Trejo, originarios de Sabinas, Nuevo León, radican en Houston desde 1988. En ese año, don Gustavo decidió traerse a su familia. Él había ido y venido con alguna regularidad ya que "su papá tenía muchos años de vivir aquí (en Houston)”, comentó Raquel, su hija. "En 1988 hubo una oportu-

\footnotetext{
${ }^{1}$ Se cambiaron los nombres para mantener la confidencialidad de la información.
} 
nidad de arreglar la residencia para quienes tuvieran algún hijo ciudadano norteamericano. Mucha gente aprovechó" (Gustavo Trejo, 14 de junio de 2007), porque eso le daba derecho a la residencia para toda la familia, lo que simplificó el trámite migratorio para su esposa y sus tres hijos. Raquel ya había empezando la preparatoria y tuvo que reiniciarla al llegar a Estados Unidos, pero pronto aprendió el idioma y se acomodó.

Este tipo de experiencia migratoria que involucra varias generaciones pone en evidencia los vínculos que históricamente han conectado a las poblaciones en ambos lados de la frontera.

El caso de Elena Benavides ejemplifica la conexión porque sus papás, mexicanos de nacimiento, se conocieron en Houston. Su mamá nació en Monterrey y su papá es de un pueblo muy pequeño entre Reynosa y Camargo, Valadeces, Tamaulipas.

Su mamá se vino un verano con sus tíos y aquí se quedó. Sus abuelos maternos son de Allende, son primos. Su abuelo creció en Harlingen, en el valle de Texas, y luego se regresó a Allende, se casó y se fue a Monterrey. Los hermanos de su abuelo se vinieron a Houston.

Dice Elena que su papá llegó de muy niño a Houston, a los 13 años. Ella cree que cruzaron la frontera y se fueron primero a California; pero ya luego se mudaron para Houston y arreglaron sus papeles con facilidad. Después se vinieron sus abuelos y sus tíos.

Ella y Sergio Hernández son los únicos informantes que pueden clasificarse como segunda generación migrante. Elena es estudiante de posgrado en Literatura española. Sergio es profesor de preparatoria y miembro de la junta escolar de su distrito; además, junto con un par de amigos, ha organizado las fiestas de celebración de la Independencia de México en su comunidad. Sus padres se casaron en Monterrey y al poco tiempo se fueron a vivir a Houston.

Ninguno de los dos tiene televisión por cable en casa y buscan activamente alternativas para mantenerse informados, reconocen la importancia de conocer el lado mexicano de las noticias que presenta Multimedios. Cada uno por su lado parece preocupado por sus raíces mexicanas norteñas, uno a través de su asociación y Elena mediante sus estudios.

Sin embargo, sus familias han tenido un papel muy importante y diametralmente opuesto en su relación con lo mexicano. Mientras que en la casa de Sergio, a través de su madre, había una preocupación por mante- 
ner tanto el idioma como la relación con la comunidad de origen, en el caso de Elena su familia materna le prohibió a su madre y ésta a su vez a ella cualquier contacto con la música popular, al grado que ahora ella dice:

Yo me defino como mexicoamericana [norteña], en mi familia no mucho, pero hay una tradición norteña, las comidas, la música, la gente [...] Yo quiero reclamar mi ciudadanía mexicana, quiero reclamar esa parte que perdí (Elena Benavides, 6 de julio de 2007).

En estos dos casos el proceso de asimilación es similar al descrito por De León (2001) en el cual la segunda generación intenta recuperar su vinculación con su comunidad de origen y, a través de esto, con su pasado y la historia de la región. Éste es uno de los procesos que Subervi (1986) identifica en los estudios que analizan el papel de los medios de comunicación en comunidades migrantes.

Por su lado, los hermanos Robles representan una alternativa diferente de las redes familiares que sustentan la migración. El mayor de ellos, Armando, vino primero a trabajar con un tío, y luego llegó su hermano José, quien apenas está estudiando la educación media. Su familia es originaria de Cadereyta, pero ahora vive en Apodaca, Nuevo León.

Susana Rodríguez, oriunda de Sabinas, Nuevo León, emigró primero a Monterrey donde estudió una carrera universitaria. En 1997 se casó con un paisano suyo que ya tenía la doble nacionalidad y se fueron a vivir a Houston. Nadie de su familia consanguínea tenía experiencia migratoria internacional, ella fue la primera, y a raíz de eso se animó su hermano quien después de una breve estancia en otra ciudad estadounidense decidió radicarse en Houston.

También se encontró otro tipo de estancia en Houston. El señor Enrique Alejo y su esposa están de visita con su hija. Él tiene su casa en Guadalupe, Nuevo León, pero desde 2006, cuando pudo arreglar su visa, pasa temporadas largas con su hija en Houston. En la fecha de la entrevista ya tenía alrededor de cinco meses y aunque no es formalmente un migrante permanente, representa una manifestación especial de la relación entre las comunidades en ambos lados de la frontera.

Mención aparte merece el caso de Luisa, de 16 años, quien va a Houston de vacaciones: pasa alrededor de dos meses al año en esa ciudad por- 
que su papá vive ahí, pero ella vive en Monterrey con su mamá. Su papá, nacido en Monterrey, se movió por primera vez a Houston en 1991, y pudo arreglar su papelería. Ella pasó unos años en Houston, todo el kínder, y se regresaron; luego ella volvió para estudiar el cuarto año de la primaria y se regresó porque no se pudo acostumbrar. Su papá va a Monterrey de fin de semana, desde el viernes, cada quince días o cada mes: "Si él quiere algo él va para allá, siempre va para allá, descansa todo el fin de semana, se va un viernes, llega el sábado y se regresa el domingo para trabajar el lunes" (Luisa, 11 de julio de 2007).

\section{Consumo de Multimedios}

Estos dos últimos casos se distinguen dada su condición de visitantes: en realidad el consumo que hacen del canal es en muchos sentidos una extensión del consumo que ya realizaban en su comunidad de origen y que pueden continuar en su lugar de destino:

Me siento como si estuviera en la casa, me doy cuenta de cosas y les hablo a mis hijos. Mi hija, que vive cerca del mercado de abastos de Guadalupe, es la que siempre también está al pendiente del canal y nos habla cuando ella oye noticias de Houston, por ejemplo de la temperatura, y se preocupa y habla para acá y “oye, que Abimael Salas dice esto”. Está más pegada a la televisión (Enrique Alejo, 5 de abril de 2008).

A pesar de que los informantes reportaron haber viajado a Monterrey o a la región circundante en fechas recientes, ninguno de ellos reportó haberse enterado de que la señal de Multimedios está disponible en Houston. Todos se enteraron por algún conocido en la ciudad estadounidense.

Es el caso de Emilia Rangel, quien se enteró del canal por un amigo de su esposo que le dijo que había visto a don Roberto Hernández Jr., y entonces cuando llegó a la casa, buscó el canal y lo encontró (Emilia Rangel, 8 de abril de 2008).

O como en el caso de Armando Robles, que se enteró por un conocido y ahora él mismo se ha vuelto un promotor del canal:

Hay gente que no sabía, que no saben [del canal] y yo se los recomiendo, les digo oye, mira, chécale los lunes a las 11 sale el programa de Chavana "Las 
Noches del Futbol", está divertido, te informas de lo que pasa en Monterrey, pues como son de allá yo les digo [...] Yo soy el que más miro el canal en la casa, me gusta el canal, desde que me dijeron, casi desde que llegué. No he tenido cable por lo mismo, porque miro ese canal (Armando Robles, 21 de abril de 2008).

Si bien los caminos que siguieron los informantes para llegar a Houston fueron diferentes, no fue posible vincular el consumo de la televisión con el proceso en sí de desplazarse; sin embargo, en todos los casos una vez que se reconoce, en el sentido de que uno se reencuentra con la señal de Multimedios en Houston, ésta fue incorporada de distintas maneras a sus vidas. En los siguientes apartados se analizan con más detalle las estrategias que permiten caracterizar el consumo de la programación de Multimedios y cómo se relaciona ésta con el lugar de origen de los televidentes.

\section{El espacio interior}

Felipe Villarreal comentó que él se enteró apenas dos meses antes de la entrevista (17 de abril de 2007) que podía ver Multimedios, a pesar de que ha estado en Houston más tiempo que la señal. Él estudia el último año de preparatoria (High School) y junto con su amigo Jaime Garza ve todos los días a don Roberto Hernández Jr. y se declararon fanáticos del club de futbol de Monterrey: los Rayados. Se juntan en la casa de Jaime, quien vive con sus abuelos, y desconectan del sistema de cable la televisión que se encuentra en el cuarto de su hermano para ver "Futbol al Día”. Los dos dicen que veían el programa desde que vivían en Monterrey y que la razón principal por la que lo ven es porque les gusta el futbol.

Es necesario comentar que "Futbol al Día" es un programa de comentarios sobre futbol, centrado en los dos equipos con sede en la zona metropolitana de Monterrey, el ya mencionado equipo del club Monterrey, o los Rayados, y el equipo de los Tigres, en el que tiene un papel central la rivalidad de estos equipos entre sí y con otros. La estación repite este programa hasta tres veces al día en diferentes horarios además de la emisión de las 2:30 pm que es en vivo; se retransmite a las 6 de la tarde, antes del noticiero y después de éste, a las 9 de la noche, y es con mucho el programa más popular entre los entrevistados. 
En un sentido amplio, el programa es una referencia importante entre los aficionados al futbol, pero por sus contenidos es esencialmente un programa local que ayuda a mantener la afición al deporte y todo lo que esto implica en términos de identificación individual y reconocimiento del otro como miembro o no de un grupo identificado con ciertos "colores" y atributos.

Ver televisión no es sólo un acto individual, también puede ser un evento en el que se comparte algo más que el gusto por un programa particular; así, podemos suponer que estos dos amigos que ven juntos la televisión están alimentando su identidad en una sociedad nueva con los elementos que recuperan de su afición al futbol y a un equipo particular de su comunidad de origen, donde su compañía refuerza lo que ven en el programa y viceversa.

Miguel Sánchez comentó que él se ha tomado el tiempo para llamar repetidamente al canal porque dice que le molestan mucho los cortes que hace la repetidora en Houston; dice que incluso ha llamado hasta Monterrey para quejarse, que ve la tele con su esposa y que es ella quien lo calma cuando empieza a hacer corajes por la señal cortada (Miguel Sánchez, 9 de abril de 2008). Esta escena, repetida más de una vez, es una experiencia ritualizada de la relación tanto con la televisión como con la comunidad de origen, en la cual la estación de Houston tiene un papel casi de antagonista.

Como la señal del canal sólo se encuentra en televisión abierta, en algunos casos es necesario desconectar el sistema de cable de la televisión para verla, lo que de alguna manera le confiere a la televisión elegida, y al espacio donde ésta se encuentra, un papel especial.

Raquel Trejo y su papá, originarios de Sabinas, Nuevo León, y radicados en Houston desde 1988, no coinciden en muchas cosas. A propósito del modo de vida en Estados Unidos, ambos dijeron estar a gusto aquí, pero don Gustavo fue particularmente crítico de las cosas que ya no tiene y de las que acá no puede hacer. No puede, por ejemplo, pasear por su colonia sin que eventualmente a algún vecino le parezca sospechoso y llame a la policía: "en México uno conoce a todos sus vecinos"; tampoco está de acuerdo en que sus hijos quieran tener carro -reconoció la necesidad e incluso la ayuda que representa, pero no le gusta-. Raquel, con un novio ruso, se mostró más bien desenvuelta y cómoda con las opciones nuevas que le ofrece esta ciudad. 
En lo que sí estuvieron de acuerdo fue en el gusto compartido por la programación de Multimedios. Comentó que su programa favorito es "Futbol al Día":

De Multimedios veo lo que veía desde que estaba allá en Sabinas, "Futbol al Día”, y como muchos años dejamos de verlo hasta que supimos que acá estaba Multimedios: Mira, le digo a Octavio [su hermano], está Roberto Hernández Junior, iya tiene el pelo blanco! (Raquel Trejo, 14 de junio de 2007).

La familia Trejo, que cuenta con tres televisiones, dejó una de ellas fuera del sistema de cable para poder ver la programación de Monterrey. La televisión que la familia Trejo separó para recibir la señal es la que se encuentra en la cocina.

La ubicación de la tele no podía ser mejor: la cocina es donde la familia Trejo se junta, donde comentan los asuntos del día y donde, como dice Raquel, es posible oír el acento de allá:

[Lo que me gusta] de Multimedios es más bien porque extraño el acento y el habla de allá, que... parece que no, ve uno la tele de aquí y sí, hablamos español, pero hablando de allá y viendo la tele de allá es con lo que yo crecí, es lo que estaba acostumbrada a oír, el habla o la entonación, no sé... es lo que yo quiero oír, cómo se habla (Raquel Trejo, 14 de junio de 2007).

En el imaginario de la circulación de mercancías entre Monterrey y Estados Unidos, lo mexicano es la tradición, la intimidad de la cocina, como en el caso de la familia de Silvia Reyna, a quienes les llevan carne seca y quesos de Villa de García, Nuevo León, de donde es originario su padre, "y tortillas de las chiquitas porque las de acá no saben igual, traen tortillas y las congelamos"; lo que viene de Estados Unidos para México es lo moderno, lo visible, la modernidad deseada. Zúñiga (1998) apunta además que detrás de estas dicotomías fronterizas está también una relación de lo propio y lo ajeno institucional construido desde las estructuras de poder. Es decir, que en la situación particular de la frontera MéxicoEstados Unidos, también debe destacarse esta dimensión de reproducción de "valores" nacionales frente a los extranjeros promovidos por las instituciones oficiales. 


\section{Conclusiones}

Este trabajo se propuso describir y relacionar las trayectorias migratorias de los televidentes de la programación de Multimedios en Houston, Texas, con su consumo de la señal y el papel que este consumo tiene en la construcción de una comunidad transnacional.

Un primer hallazgo importante se refiere a la manera en que los dos informantes de segunda generación buscan activamente su propia identidad como mexicano-americanos con la televisión teniendo un papel en esta búsqueda de lo mexicano-norteño que Elena Benavides identifica como una pérdida. Mientras que el resto de los informantes o bien están reconstruyendo su consumo de la programación de Multimedios en este nuevo entorno o simplemente continúan con su consumo habitual. Ejemplo del primer caso es el par de amigos que se encuentran frente a la televisión como fans del equipo de futbol Monterrey en Houston o la familia que descubre que don Roberto Hernández Jr. ya tiene canas.

Por otro lado, de las entrevistas realizadas resultó que en algunos casos la búsqueda activa del canal en la señal aérea puso en evidencia la importancia tanto del espacio donde se ve la televisión como la experiencia de compartir la migración con otras personas integrándolas a esta nueva posibilidad de vivir transnacionalmente al mismo tiempo que se encuentra un espacio íntimo que remite al hogar original.

Ante una situación de inestabilidad que ponga a prueba la seguridad ontológica del individuo, la primera generación recurre a sus experiencias y a una serie de habilidades socialmente construidas en el país de origen, incluido el consumo de televisión (Silverstone, 1993, 1996); pero la generación siguiente carece de esa experiencia "de origen" y tiene que construir sus habilidades en las condiciones del país receptor (Chan y Ma, 2002:13) para enfrentar las mismas situaciones conflictivas.

Aprendemos a ver la televisión desde muy chicos, aprendemos su lenguaje, tenemos una vida de experiencias compartidas, y el migrante se lleva este conocimiento consigo. Los estudiosos de la migración han encontrado que los vínculos de Monterrey con algunas ciudades de Texas se apoyan en redes sociales, especialmente familiares, que les abren camino y a la vez sirven de enlace con las comunidades de origen (Sandoval, 2006). Estas redes familiares anclan perfectamente al migrante en términos de su 
definición identitaria y le posibilitan el mantenimiento de la comunicación efectiva.

La llegada de la televisión abre la posibilidad de que el mundo simbólico ya conquistado con la migración tenga un elemento más de arraigo, sobre la base del espacio virtual que representa la programación televisiva. La televisión regional en este marco transnacional migratorio podría cumplir funciones tan elementales como la seguridad que puede proveer al migrante una imagen de su ciudad. También puede ser algo más complejo al contribuir a validar una identidad, enfrentada en una sociedad nueva, lo que permitiría a su vez negociar con la nueva situación desde una posición de base más fuerte.

Así, es posible concluir que hay elementos que condicionan la interacción de los sistemas sociales que probablemente puedan ser explicados revisando la historia del sistema: cómo se conformó, qué elementos se integran al sistema y en qué orden, y cómo ese arreglo histórico explica su conformación actual y ninguna otra.

\section{Bibliografía}

Barker, C. (2003), Televisión, globalización e identidades culturales, Barcelona, Paidós. Brah, A. (1996), Cartographies of Diaspora, Londres, Routlege.

Bernard, H. R. (1995), Research Methods in Anthropology, Walnut Creek, Altamira Press-Sage Publications, California.

Carmona, M. S. (2007), "Reconfiguración estratégica de las industrias culturales de Nuevo León (prensa, radio y televisión) ante los cambios del entorno socioeconómico", en L. Hinojosa (comp.), Estudios de cultura, comunicación y tecnologías de la información: tesis doctorales y avances de investigación. Vol. I, Universidad Autónoma de Nuevo León, Monterrey, Nuevo León.

Cerutti, M. (2000), Propietarios, empresarios y empresa en el norte de México, Siglo XXI, México.

Chan, J. M. y E. Ma. (2002), "Trasculturating Modernity: A Reinterpretation of Cultural Globalization”, en Joseph M. Chan y Bryce T. McIntyre (eds.), In Search of Boundaries: Communication, Nation-States and Cultural Identities, Ablex Publishing Westport, Connecticut y Londres.

Davis, E. (2005), Houston.MediaWeek; 8/22/2005, Vol. 15, 30: 9-14. Disponible en $<$ http://search.ebscohost.com/login.aspx?direct $=$ true $\& d b=$ buh $\& A N=20436$ $762 \&$ site $=$ bsi-live $>$.

De León, A. (2001), Ethnicity in the Sunbelt. Mexican Amercians in Houston, Texas A\&M Press, College Sation, Texas, Estados Unidos. 
Fortier, A. (2002), “Bringing it all (back) Home: Italian-Canadians' Remaking of Canadian History", en Paul Kennedy y Victor Roudomelof (eds.), Communities across Borders: New Immigrants and Transnational Cultures, Routledge, Londres y Nueva York.

García-Palafox, G. y G. Rangel (2006, 31 de octubre), TV: Sólo queda una versión hispana de los hechos. Rumbo de Houston. Disponible en <http://www. rumbonet.com $/$ rumbo/articulo. asp?idart $=435886$ \&idcat $=3702>$.

Gerbner, G. y L. Gross (1976), "Living with Television. The Violence Profile", Journal of Communication, 26 (2).

, L. Gross, M. Morgan y N. Signorielli (1996), "Crecer con la televisión: perspectiva de aculturación”, en Jennings Bryant y Dolf Zillmann (comps.), Los efectos de los medios de comunicación. Investigaciones y teorías, Paidós, Barcelona.

Habermas, J. (1993), La lógica de las ciencias sociales, Rei, México.

Hernández León, R. (1997), "El circuito migratorio Monterrey-Houston", Ciudades 35, 26-33.

(1999), “iA la aventura!”: Jóvenes, pandillas y migración en la conexión Monterrey-Houston”, en Gail Mummert (ed.), Fronteras Fragmentadas, El Colegio de Michoacán, cidem, Morelia, Michoacán.

(2002), Urban Origin Migration from Mexico to the United States: The Case of the Monterrey Area, disertación doctoral no publicada, Universidad Estatal de Nueva York, Binghamton, Estados Unidos.

(2004), "Restructuring at the Source. High-skilled Industrial Migration from Mexico to the United States", Work and Occupations, 31 (4): 424-252.

(2008), Metropolitan Migrants: The Migration of Urban Mexicans to the United States, University of California Press, Berkely y Los Angeles.

Kanellos, N. y H. Martell (2000), Hispanic Periodicals in the United States. Origins to 1960: A Brief History and Comprehensive Bibliography, Arte Público Press, Houston, Texas.

Mayer, V. (2001), "From Segmented to Fragmented: Latino Media in San Antonio, Texas", Journalism and Mass Communication Quarterly, 78 (2): 291-306.

Morgan, M. y J. Shanahan (1991), "Television and the Cultivation of Political Attitudes in Argentina", Journal of Communication, 41 (1). 88-103.

Pedroza, G. (2004), "La radio comercial en Monterrey. Apuntes para caracterizar una región”, en B. Russi (ed.), Anuario de Investigación de la Comunicación CONEICC XI, CONEICC, México.

Pinkerton, J. y S. Carroll (2008 17 de abril), "Raid on Shipley Headquarters: 20 Arrested in Federal Roundup: Employees Face Deportation; Chain Working with ICE", Houston Chronicle, en < http://www.chron.com/CDA/archives/archive. mpl?id=2008_4551162>. 
Portes, A. (2005), "Convergencias teóricas y evidencias empíricas en el estudio del transnacionalismo de los inmigrantes", Migración y Desarrollo, Primer Semestre 2005.

Ruiz, J. I. (1999), Metodología de la investigación cualitativa, Universidad Deusto, Bilbao.

Sandoval, E. (2006), Movilidad, circulación e intercambio en el espacio social Monterrey, N.L.-San Antonio, Texas, disertación doctoral no publicada, CIESAS, México.

(2008), "Memoria y conformación histórica de un espacio social para el consumo entre el noreste de México y el sur de Texas", Relaciones. Estudios de Historia y Sociedad, 114 V. XXIX, 235-273

Silverstone, R. (1996), Televisión y vida cotidiana, Amorrortu, Buenos Aires. (1993), "Television, Ontological Security and the Transitional Object", Media Culture and Society, 15, 573-598.

Subervi-Velez, F. (1986), "The Mass Media and Ethnic Assimilation and Pluralismo: A Review and Research Proposal with Special Focus on Hispanics", Communication Research, 13-1, 71-96.

Zúñiga, V. (1998), "Representaciones infantiles de la frontera y del espacio nacional (materiales para una geografía cultural de la frontera MéxicoEstados Unidos)", en Víctor Zúñiga (coord.), Voces de la frontera. Estudios sobre la dispersión cultural en la frontera México-Estados Unidos, Universidad Autónoma de Nuevo León, Monterrey, México. 
